\title{
APPLICATION OF SIMULATION TOOLS IN THE PROCESS OF CASTING AND PROCESSING OF ALUMINIUM CASTINGS
}

\author{
Miriam PEKARČÍKOVÁ, Peter TREBUŇA, Marek KLIMENT \\ TUKE - Technical University of Kosice, Kosice, Slovak Republic, EU, \\ miriam.pekarcikova@tuke.sk,peter.trebuna@tuke.sk,marek.kliment@tuke.sk
}

https://doi.org/10.37904/metal.2019.995

\section{Abstract}

Ergonomic rationalization of workplaces and the creation of optimal conditions for work performance have a positive impact on worker satisfaction, thereby enhancing efficiency and productivity at work and reducing employee turnover. Therefore, for manufacturing companies where human labor is the dominant factor, efficiency gains are very important for ergonomic rationalization. The trend in projection of layouts is using the simulation software to move from classical design to digital and virtual design. A great advantage of such applications is that, they allow creating visual space of workplace with taking into account the ergonomics requirements on workplaces already in the process of design. The article is focused on the application of simulation tools in the creation of the casting process model and the simulation of technological operations on the workplace of casting processing. The goal is to optimize the workplace layout in terms of ergonomics by using the Tecnomatix Jack software module and the Microsoft Kinect. Linking Tecnomatix Jack with Microsoft Kinect creates area for simulating work movements right at their performance. Creating a static model of the work position in Tecnomatix Jack and then placing a person in the digital model and moving it through Microsoft Kinect allow moving real worker movements into the virtual environment and evaluating the worker's current workload. The advantage of simulation modelling in the selected software is to propose an ergonomic design before the implementation phase, thereby avoiding back-ups and the need to make changes later, at a time when corrections are more complicated and costly. The results from realized ergonomics analyses were used to improve the ergonomic conditions of selected workplaces like casting and inspection of castings.

Keywords: Simulation, process, casting, ergonomics, TX Plant Simulation

\section{SIMULATION TOOLS FOR ERGONOMIC ANALYSIS}

Ergonomic software allows to create a virtual workplace model and simulate human movements. The comprehensive range of ergonomics parameter simulation tools helps to generate optimal solutions for relationships and interactions between the worker and the product they use or the equipment they serve. Virtual modeling, simulating, optimizing and designing design options from an ergonomic aspect greatly reduce process time and cost $[1,2]$. The advantage of virtual simulation is to design the ergonomic design for the first time, avoiding back-ups and the need to make changes later, when the corrections are more complicated and costly. By simulating the behavior of the human factor, it is possible to reduce workplace accidents and thus reduce the cost of accidents at work in the process of designing workstations. The result of ergonomic simulation is the evaluation of the working position of the cell or the production process. The assessment is based on industry standards, so it is possible to identify a potential source of injury and make adjustments in time. For example, programs such as CATIA, DELMIA V5 Human, Tecnomatix Jack and others can be used to simulate workplace ergonomics. The application of the Tecnomatix Jack simulation program in the optimization of the workplace ergonomics and the use of Kinect in the evaluation of the ergonomic load is processed $[3,4]$.

\subsection{Application of Tx Jack module in ergonomics}

Tecnomatix Jack is one of the products of Siemens PLM software focused on ergonomics and human factor. It offers ergonomic workplace solutions and work operations by placing a precise biomechanical model of man 
in a virtual environment. By assigning a task and monitoring its performance, it is possible to obtain information about the worker's range and visual capabilities, as well as to predict the comfort of the work environment. It is a visual simulation tool that allows to design any environment directly in the program or import CAD objects from external software. It is possible to create a workload simulation and use Kinect to analyze workloads. The virtual man provided by the software is based on the knowledge of ANSUR88, the National Health and Nutrition Examination Survey, and others. The virtual man consists of 69 segments, 17 of which are realistic spines and 16 hands. Joint and force limits are derived from NASA studies. [1]

\subsection{Potential of Microsoft Kinect in the connection with Tx Jack module}

An interface has been developed between the module Tx Jack and Microsoft Kinect. This offers an original way of human simulation. Using the 3D radiation map, Kinect captures body part movements. Areas exposed to radiation can be analyzed with two object tracking modes:

- $\quad$ Posturing: focus on maneuvering and character gestures during the event.

- Explore Surrounding: focus on mapping the model and body posture.

In the Tx Jack, it is possible to track and evaluate workers during work, focus on optimum work positions, conditions associated with overloading workers, and gain insight into positions bordering (or already exceeded) with physiological limits that result in pain in the hands, spine, or muscles. In addition to the Kinect module, we know the Occupant Packaging Toolkit (OPT) and the Task Analysis Toolkit (TAT). OPT analyzes focus on the interior, that is, the simulation of the movement of characters in vehicles, machines with control and the like. It focuses on the performance and comfort of characters in different simulation activities. The TAT module evaluates the risks at varying load ranges, positions, muscle usage, movement frequency, and working time. This module contains a set of analyzes, that serve as a tool used to reduce the workload of a person/worker in a work environment. [2]

\section{CREATION THE SIMULATION MODEL OF WORKPLACE OF CASTING}

Ergonomic analysis was performed at the casting and exit control workplace. Through the completion of the questionnaire by workers, data about the high and weight of employees were obtained, which were subsequently averaged and based on the results, human models were created at the respective workplaces. With Tx Jack modul ergonomic analyzes and solutions for optimizing these workplaces were proposed.

\subsection{Model and simulation of workplace of casting}

Before performing the ergonomic analysis, a model of the casting operation was created in the Tx Jack module (Figure 1). The dimensions of the objects that are part of this workplace were obtained by own measurement and the dimensions of the casting press were provided by technical drawings from the company's management. The dimensions of the stairs, which are present at this workplace and represent a relatively high risk of injury to the worker, were also measured.

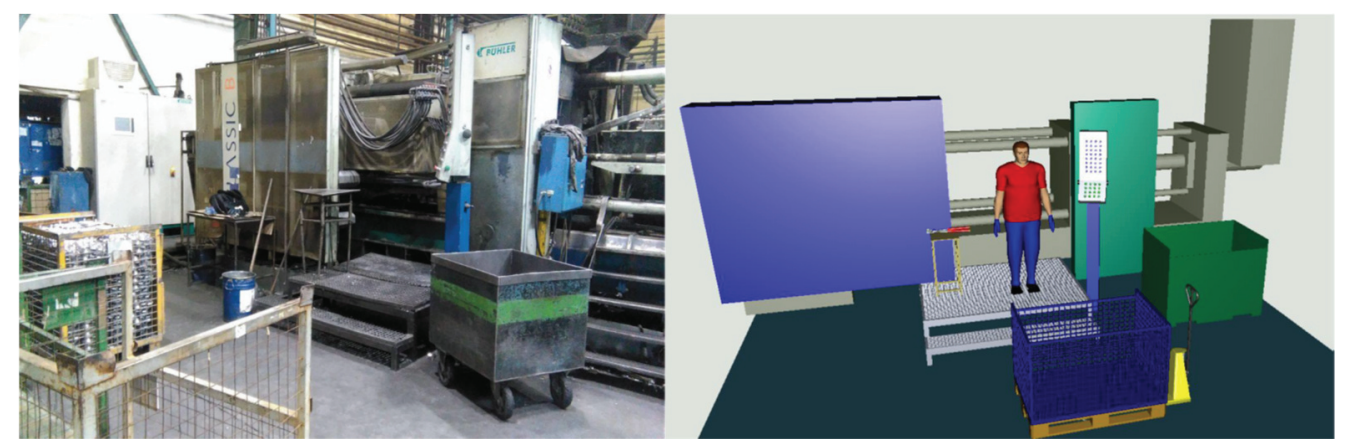

Figure 1 a) Workplace of casting b) Model of workplace of casting 
Ergonomic analysis OWAS was launched after the worker activity simulation was created, as this analysis determines the relative discomfort of the work position, with emphasis on the position of the back, legs and hands. OWAS analysis evaluated risk category 2 (Figure 2), which poses a potential for musculoskeletal impairment and corrective action should be taken in the near future. It is also necessary to take into account the frequency of the worker's movement on the stairs during the change, since during the one change 1600 pieces of castings are made (in the case of a 4 -fold form, i.e. 400 pieces of castings trees).

The castings must be stored in the gitterbox. However, a worker whose task is to put the casting into the gitterbox must go up the stairs to the prepared gitterbox and then after the casting, go up the stairs. However, this means that the worker will pass this route about 800 times for a change, which may have a negative impact on his or her musculoskeletal system.

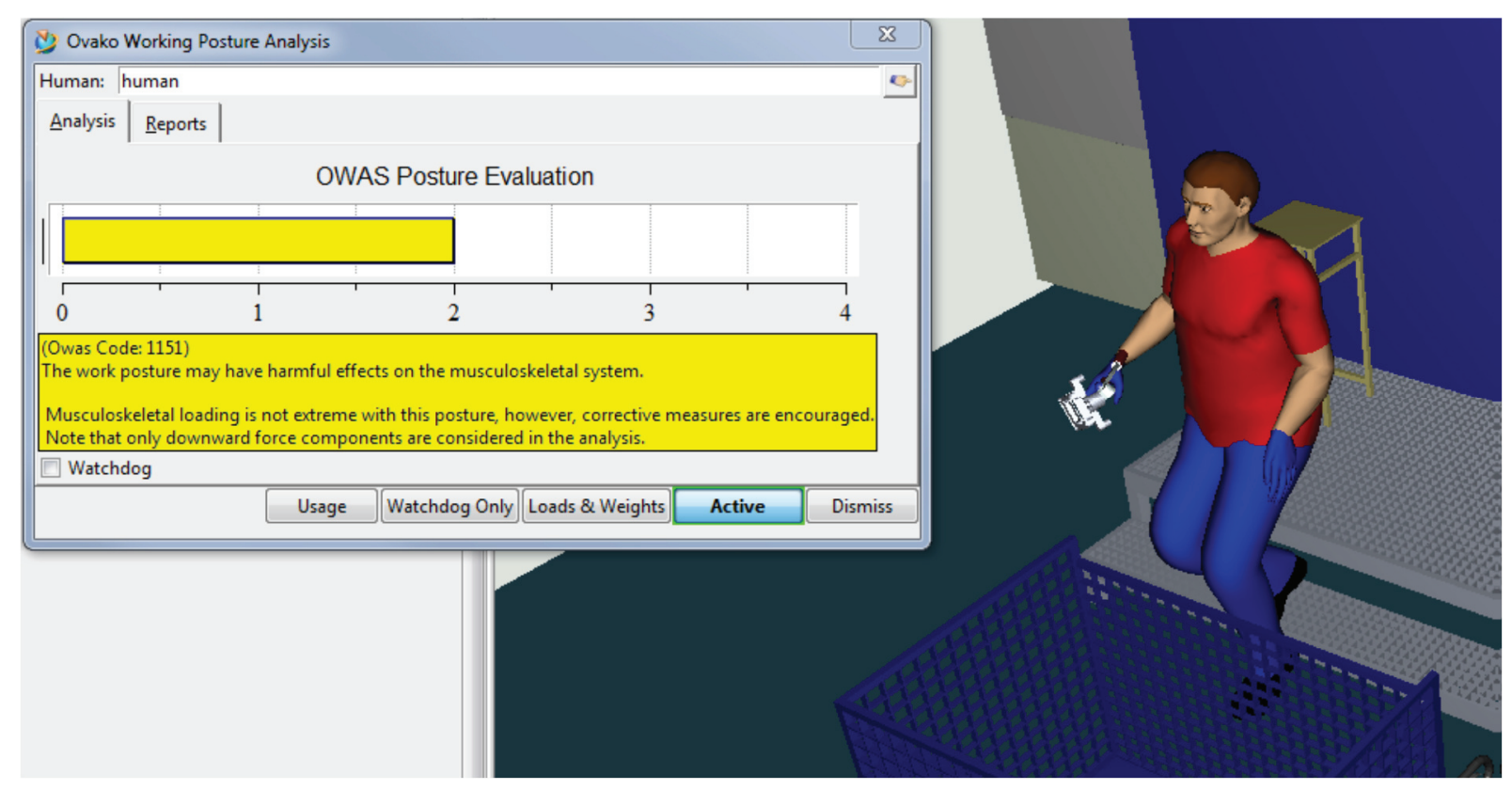

Figure 2 OWAS analysis evaluation - workplace of casting

\subsection{Model and simulation of final inspection workplace}

The task of the worker before the final inspection is to insert 100 pieces of castings from the prepared gitterbox of the previous trimming operation into the blasting equipment. An empty gitterbox is ready in front of this device, and blasted pieces of casting fall after the blasting process. The loaded gitterbox is transported by the pallet truck to the final inspection site. He selects the controlled piece from the prepared gitterbox, checks it and then places the checked cast into the appropriate box. Four boxes are placed in front of the worker, into which the worker, according to the distribution of the right and left casting cavities, divides the casts accordingly. The worker pours the filled boxes into the ready gitterbox for the customer and continues to check. For the change he checks 2600 pieces of castings.

Gitterbox for customers should contain 400pcs of castings. However, it often happens that it contains more pieces, because the worker himself has to count the checked pieces of castings.

The model of the output control workplace (Figure 3) contains all the objects in real dimensions according to the actual workplace. An ergonomic analysis of OWAS (Figure 4) was also launched after simulating the worker's activity during the inspection, which evaluated the risk category number 2 when selecting castings from the gitterbox for inspection. 

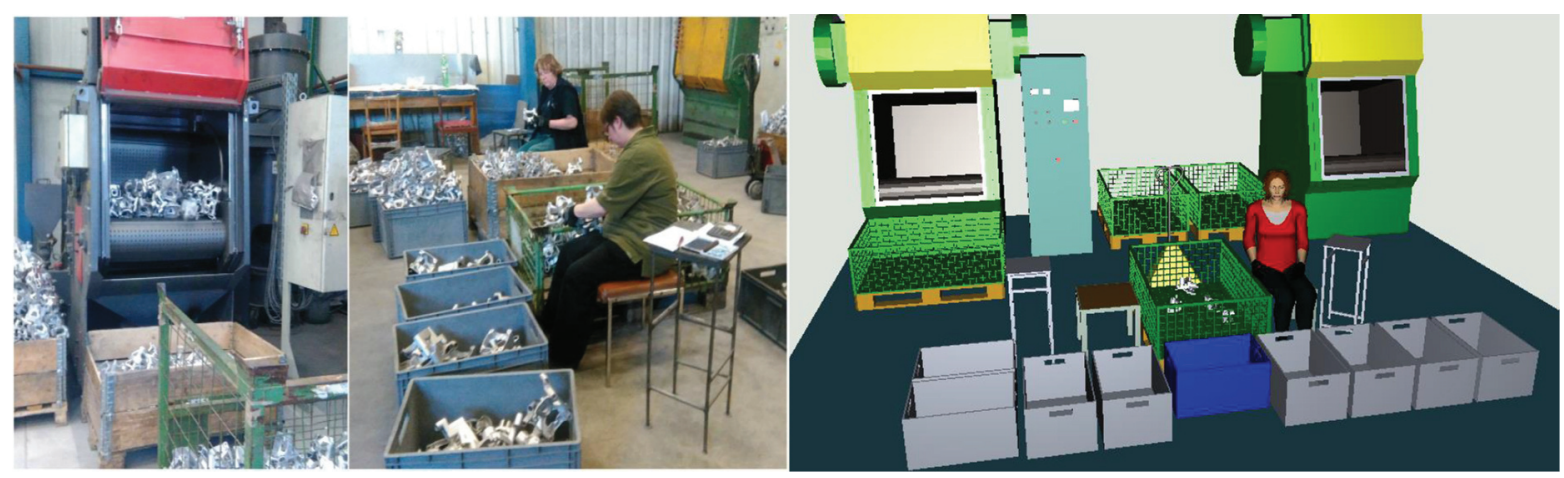

Figure 3 a) Blasting equipment and final inspection workplace b) Model of final inspection workplace

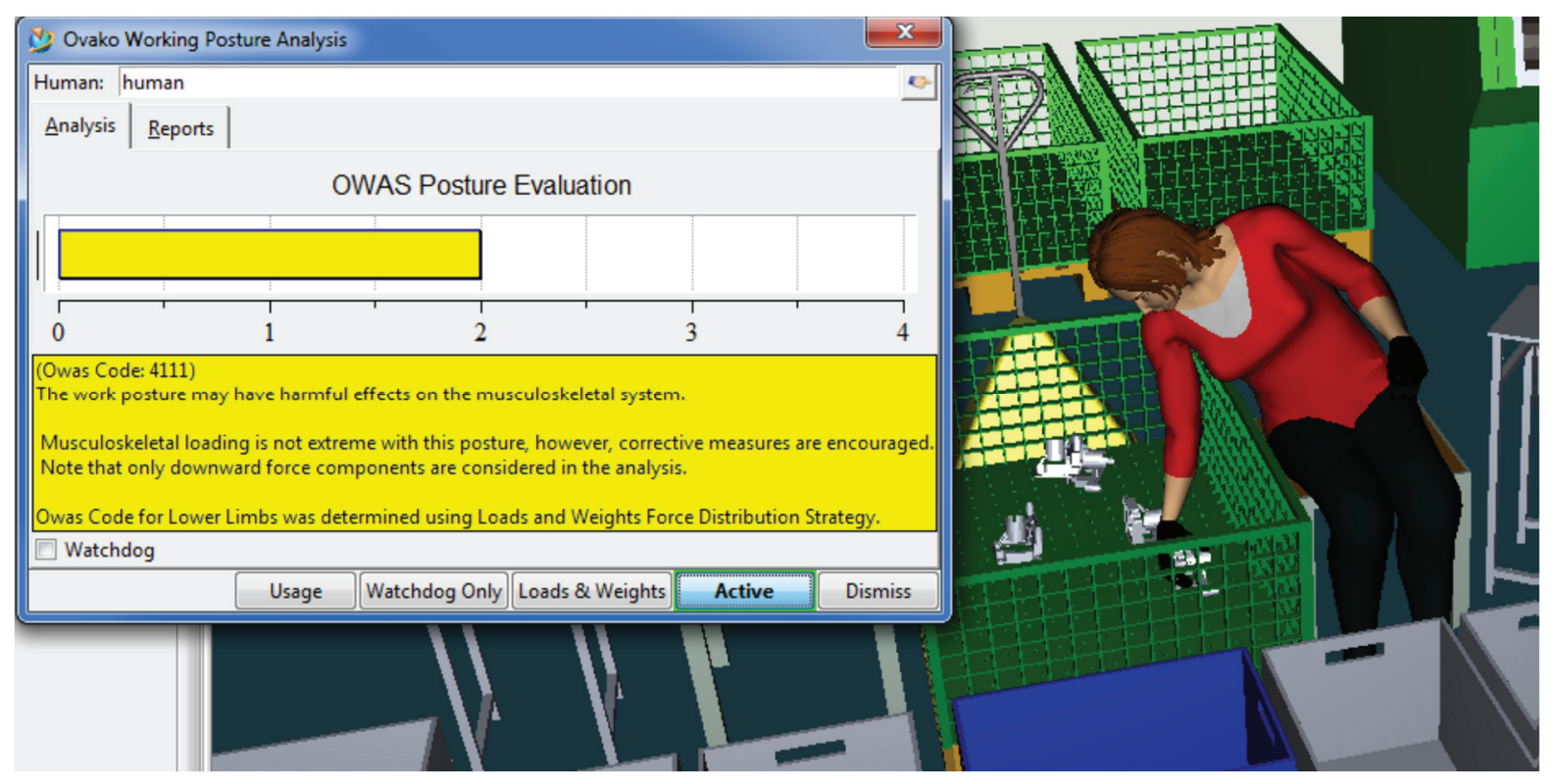

Figure 4 OWAS analysis evaluation - final inspection workplace

By the simulation of the activity when a worker lifts a filled box with checked castings, an ergonomic analysis RULA (Figure 5) was launched to evaluate the load on the individual body parts. The result of analysis was that the worker is in the risk category 7 , that's why the need of corrective actions was proposed.

The counting of the checked pieces for such a number of castings can also be considered as a certain load on the worker who must also subsequently sort these pieces according to the right and left casting cavities. However, the final inspection workstation is
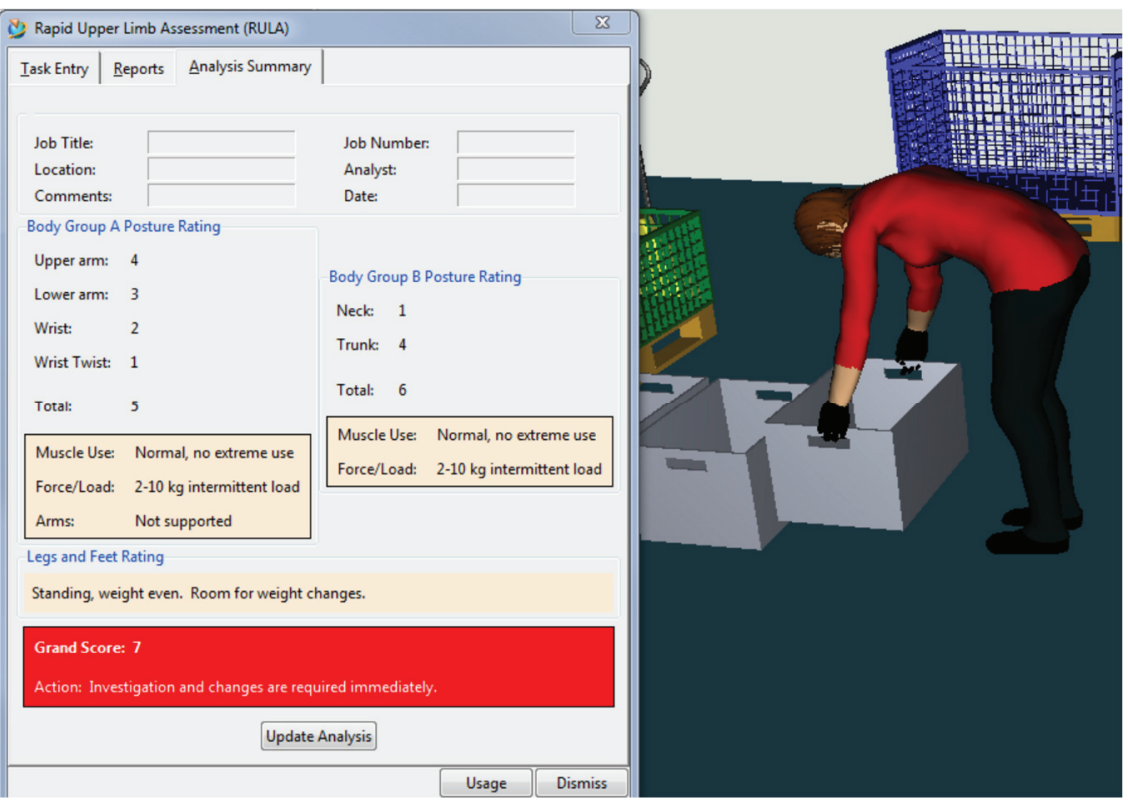

Figure 5 RULA analysis evaluation - final inspection workplace 
also equipped with trolleys for blasting machines that are no longer used by undetected causes. The trolleys were purchased for use when the blasting was completed, where castings were to be placed directly from the blasting equipment. These trolleys should be used by workers instead of a gitterbox, i.e. take the controlled castings directly from the trolleys.

\section{SIMULATION THROUGH KINECT MOTION SENSOR}

Simulating simple worker movements was also possible by using the Kinect sensor in the Tx Jack software module environment. Since it was not possible to place the Kinect motion sensor in a real workplace environment, simulation was carried out in the laboratory at the Technical University of Kosice. Because the program has a limited object library, it was necessary to create specific workspace models using a different software tool (Inventor, NX, etc.). 3D objects from the site were modeled in the Solid Work software and then imported into the Tx jack environment where the workplace scene was created. Kinect was positioned 840 $\mathrm{mm}$ above the ground so there were no objects in the sensor's field of view. The worker's movements were performed directly in front of the sensor, allowing perfect capture of points on the human body to simulate worker movements. However, the simulation also required the rotation of the character in the space, which did not allow for the direct capture of points by the sensor. This caused inaccurate movements of the worker in the virtual model and the misleading result of ergonomic analysis. But with Kinect, the operator's range of capabilities was verified. Through video recording at a real casting site, the worker's activities were repeated before the motion sensor in the premises equipped with the appropriate technology (Figure 6).

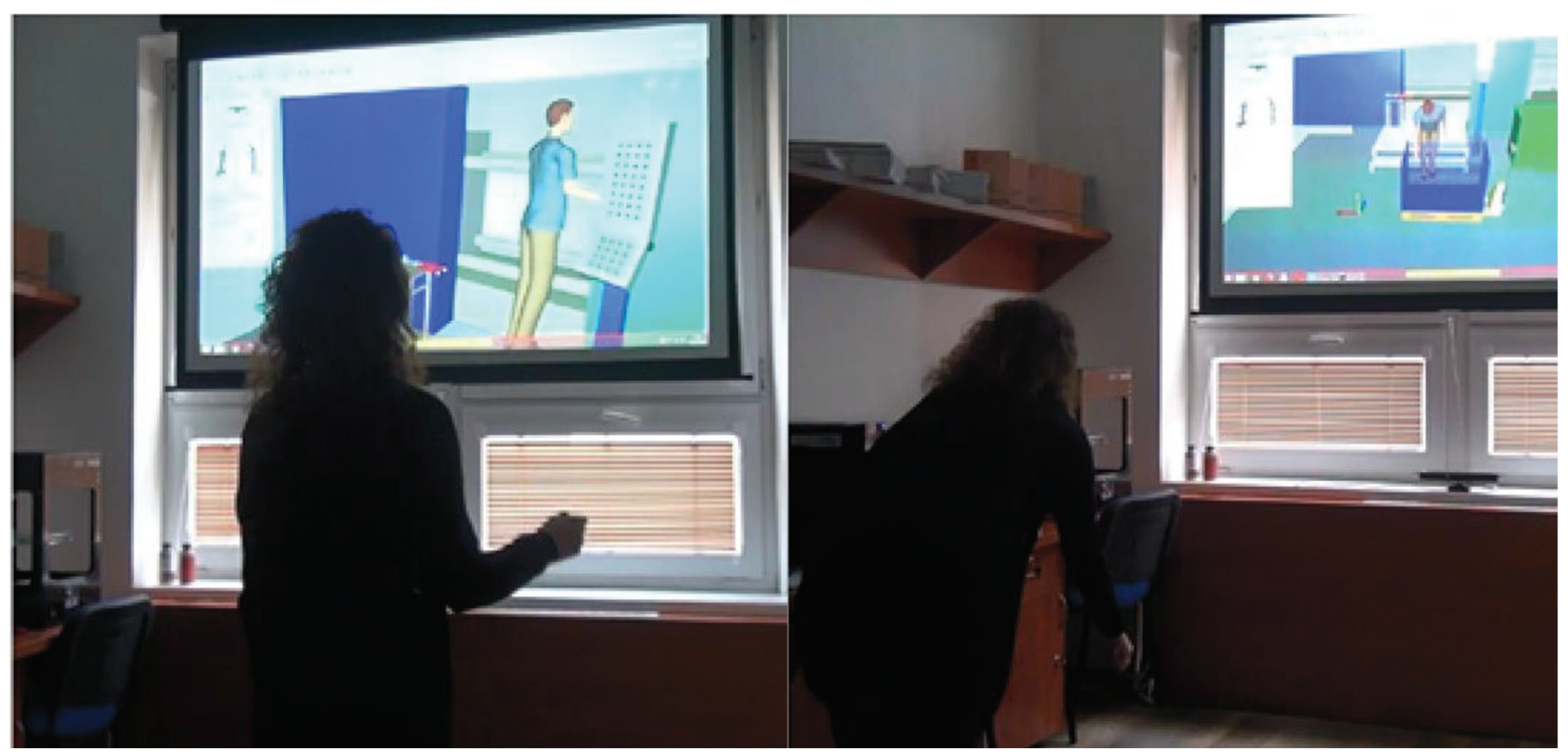

Figure 6 Simulation workplace of casting using Kinect

\section{PROPOSED SOLUTIONS TO THE PROBLEMS AND THEIR IMPLEMENTATION}

Based on ergonomic analyzes, consultations with the company management and also after consultation with relevant employees, solutions were designed to improve the ergonomic conditions of selected workplaces. In agreement with the management of the company, several options were selected from several options, the implementation of which the company is to implement in the near future.

\subsection{Design of ergonomic improvement of the output control workplace}

As mentioned above, at the workplace of a technological operation, the stairs were an object that posed a threat to the damage to the locomotor system and also a threat of possible injury. As a solution, a work platform 
(Figure 7) was designed with dimensions in $\mathrm{mm}$ of $2400 \times 2400 \times 400$, which would prevent the worker from walking the stairs frequently. A handling table and a gitterbox would be placed on this platform, which could be placed on the proposed platform with a forklift. The upper part of the platform would be a steel grate that would prevent the worker from slipping on a smooth surface. The work platform would also fulfill the task of maintaining relative cleanliness in the workplace. Impurities from the casting environment would come through the grille into the interior of the platform where the sheet is positioned at an angle to accumulate dirt on one side of the platform. The side panels of the door can be used to clean the inside of the platform at any time. In this case, the frequency of cleaning (e.g. once a week) could also be reduced.

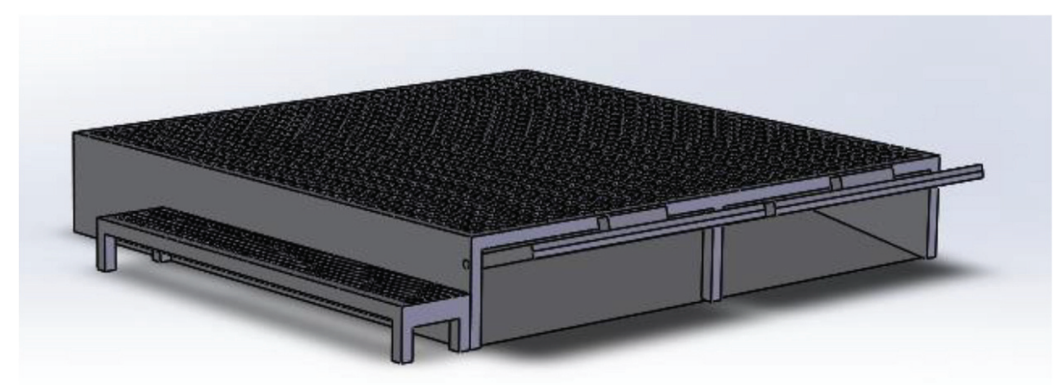

Figure 7 Designed work platform for work station of casting

After implementing the proposed solution in the workplace, the ergonomic analysis of OWAS (Figure 8), which assessed risk category number 1 , was re-performed. This means that the working position is normal, with no harmful effects on the musculoskeletal system and requires no corrective action. The implementation of the work platform has prevented stairs from being walked on and thus reduced the risk of slipping or stumbling.

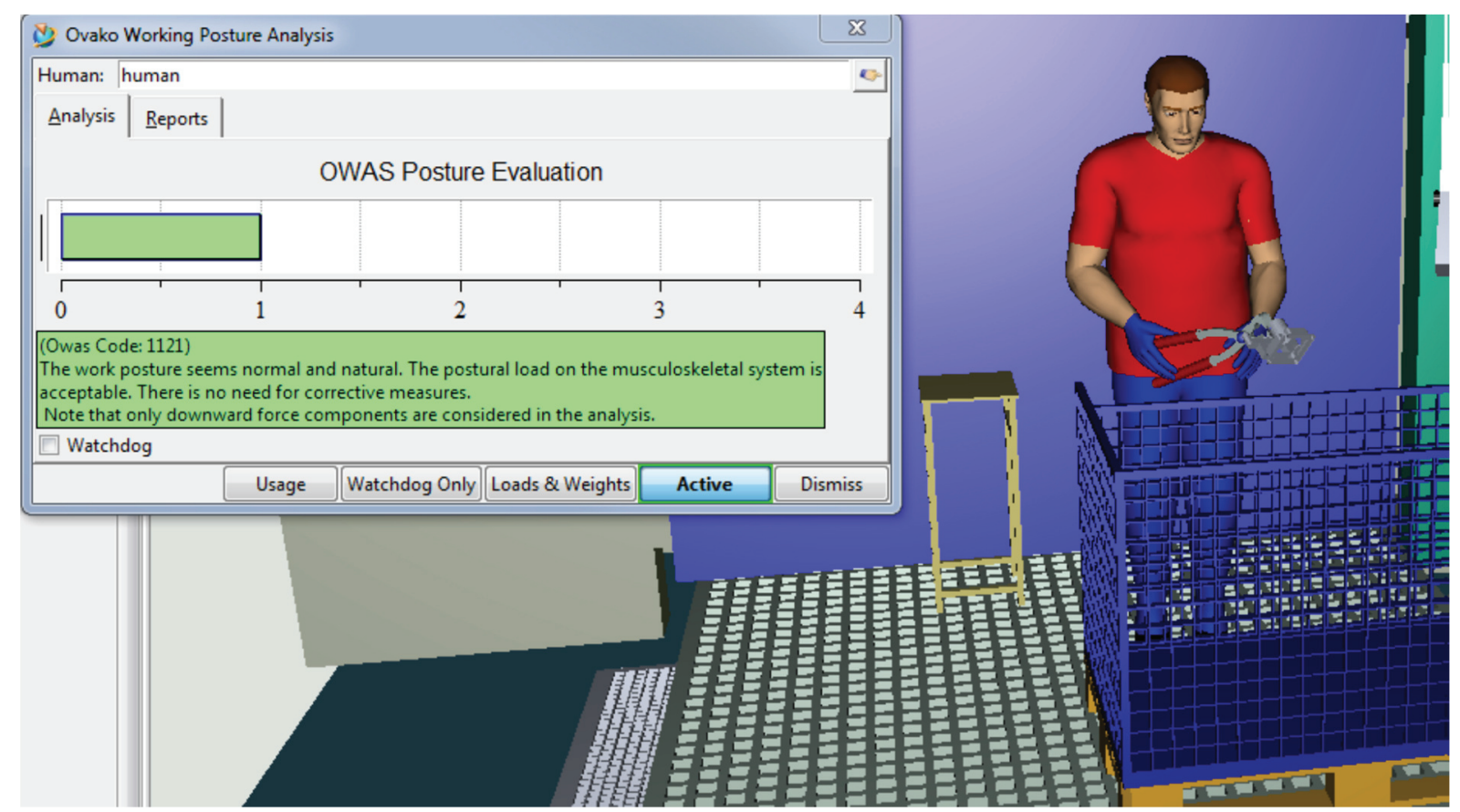

Figure 8 Analysis OWAS after implementation of the proposal

\subsection{Design of ergonomic improvement of the output control workplace}

The design of a solution for ergonomic improvement of the output control workplace is preceded by a proposal to use the gitterbox, divided into the same two parts, at the previous trimming workplace. Using a split gitterbox would make it easier for a control worker to sort the casts side by side on the right and left casting cavities. 
Contrary to the previous gitterbox, the proposed gitterbox would differ by mounting four handles on the gitterbox construction. A dividing material would be inserted in the handles and a gittebox for other operations, if necessary. For another type of casting, it would be possible to remove the separating material easily and at any time. Another suggestion for improving the output control workplace is the belt conveyor. The proposed conveyor would be designed to count and move checked casts to a ready gitterbox for the customer. The sensor would record the number of pieces and the control panel would allow the necessary number of pieces to be set. After reaching the specified number, the conveyor waist would stop and the control sign would light up. The conveyor would be placed on wheels with brakes for better handling and possibly locking (Figure 9). The implementation of the proposed belt conveyor would eliminate the activity of lifting and moving filled boxes with checked pieces to the ready gitterbox of the customer.

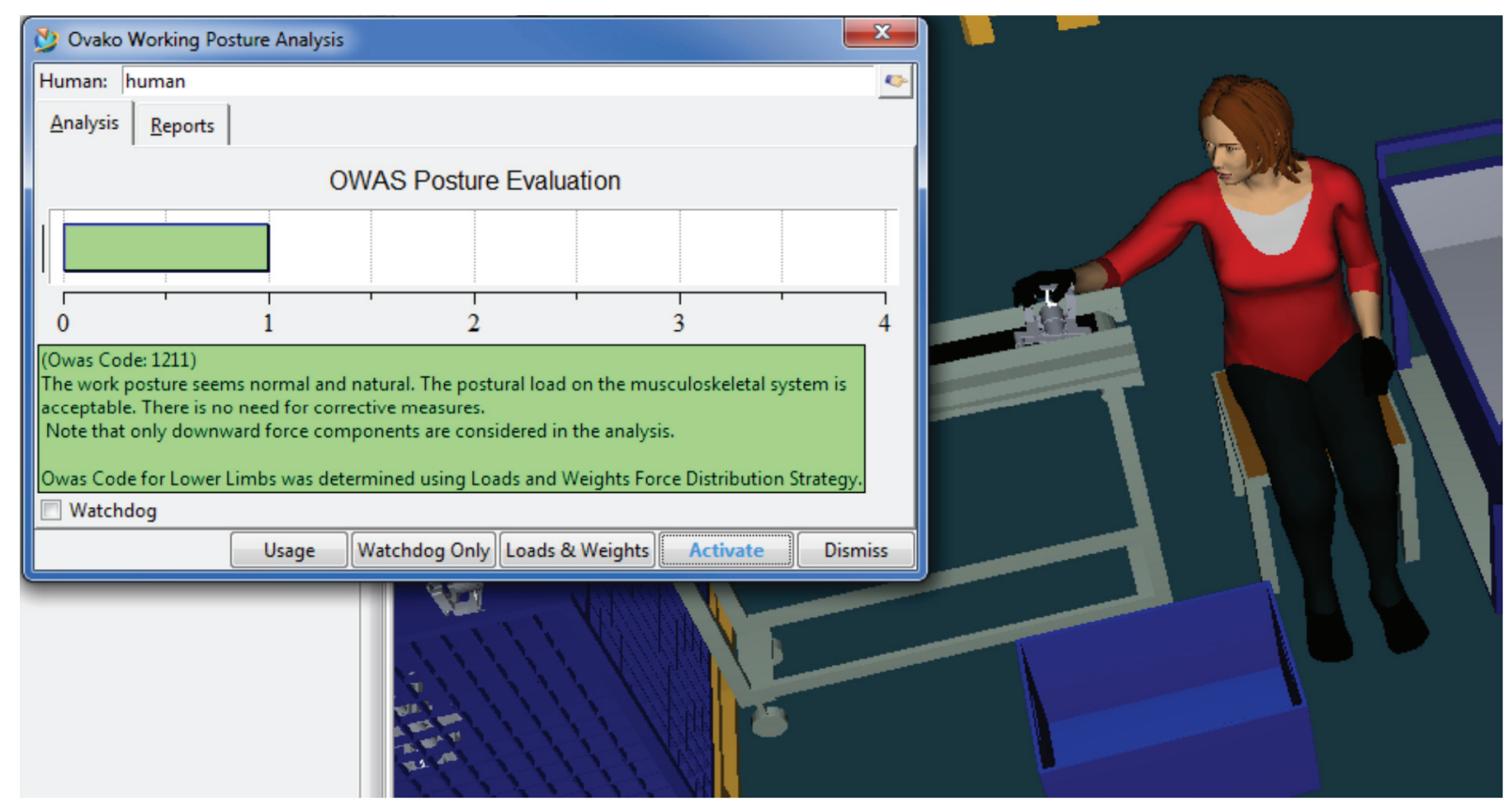

Figure 9 Evaluation of OWAS analysis by placing the castings on conveyor belt

Ergonomic analysis of OWAS after implementation of the workplace design solution evaluated the risk category number 1 in both cases. This means that the worker's position has no harmful effects on the locomotive organs.

The first and most important task in creating the simulation model is to define the goal. The model is a simplification of reality, so it is necessary to make it clear to what purpose the model should serve and what questions to answer. It must also include all elements of the real system that are critical to the defined target. It is necessary to collect existing data in a suitable form and thus build the model by creating individual elements and adjusting their properties. To create 3D models in Tx Jack, the selected workplace was analyzed in detail and then modeled in the environment of the software.

\section{CONCLUSION}

The use of Kinect is not beneficial in every situation. When using Kinect, it is necessary to prepare the device so that it is located at an optimal distance from the place of operation. Choice of location is very important. Kinect placed too close may distort movements. Also, the obstacle in front of the helper is a problem in sensing movements, i.e. it is convenient to create a virtual environment and use it to simulate the actual movements needed to perform the operation. Deformation of the virtual skeleton can be also caused by accent lighting or light environment. The main disadvantage of Kinect is lower accuracy. To solve this problem, it is appropriate 
to use two Kinect (front and side record). Also, a combination with data gloves is suitable variant to get a more accurate result. This opens further scope for research in this area in the context of Industry 4.0. [5-8] Such laboratories can be created not only at universities but especially in companies that can apply the simulation results directly into practice. Use of virtual reality glasses, respectively. Creating a virtual cave is currently another stage of development within the educational and scientific spheres for measuring and evaluating people's work operations. Of course, there are other tools that are linked to ergonomic software. It is a measurement of the workload of the worker directly on the work shift. The aim of such integrated technology is to evaluate the workload of the employee comprehensively in the scope of the entire work change. The measurement is focused on the workload of small muscular groups of the forearm, wrist or palms. Based on the measured values it is possible to objectively assess the ergonomic possibilities of the workplace, resulting in the elimination of organic changes in individual body systems. Measurement by such technologies is intended for objectivization of physiological parameters by continuous monitoring of physical load and subsequent processing of physiological data.

Technological advances are rapidly pushing the boundaries between the work tasks that people carry out and that are provided by machines and algorithms. [9-12] The employee will no longer directly provide the creation of added value, but his job will focus on monitoring processes and robots, maintaining equipment, evaluating data and processing analyzes, etc. not only in big company but also in medium and small. [13-15] Transformation should aim at using new technologies to achieve higher levels of production and consumption efficiency, expanding into new product markets that reflect the needs of the global consumer base. In the meantime, however, these ways of improving the quality of working conditions will be necessary.

\section{ACKNOWLEDGEMENTS}

\section{This article was created by implementation of the grant project VEGA 1/0708/16 Development of a new research methods for simulation, assessment, evaluation and quantification of advanced methods of production and APVV-17-0258 Digital engineering elements application in innovation and optimization of production flows.}

\section{REFERENCES}

[1] GASOVA, M., GASO, M., STEFANIK, A. Advanced Industrial Tools of Ergonomics Based on Industry 4.0 Concept. In Procedia Engineering. vol. 192. Transcom 2017 12th International Scientific Conference of Young Scientists on Sustainable, Modern and Safe Transport. High Tatras, Grand Hotel Bellevue, Slovakia. 2017, pp. $219-224$.

[2] BANGSOW, S. Tecnomatix Plant Simulation. Modeling and Programming by means of examples. Springer. 2015.

[3] LENORT, R., STAS, D., SAMOLEJOVA, A. Heuristic Algorithm for Planning and Scheduling of Forged Pieces Heat Treatment, Metalurgij [online]. 2012. vol. 51, no. 2, pp. 225-228 [viewed 2018-09-25]. Available from: https://hrcak.srce.hr/74856.

[4] RAJNOHA, R., GÁLOVÁ, K., RÓZSA, Z. Measurement of Impact of Selected Industrial Engineering Practices on Companies' Economic Performance. Inzinerine Ekonomika-Engineering Economics, 2018, vol. 29, no. 2, pp. 176187.

[5] GREGOR, T., KRAJCOVIC, M., WIECEK, D. Smart Connected Logistics. In Procedia Engineering. vol. 192. Transcom 2017 12th International Scientific Conference of Young Scientists on Sustainable, Modern and Safe Transport. High Tatras, Grand Hotel Bellevue, Slovakia. 2017.

[6] ROSOVA, A. The system of indicators of distribution logistics, transport logistics and material flow as a tool of controlling in logistics enterpise, Acta Montanistica Slovaca [online]. 2010. vol. 15, no. 1, pp.67-72 [viewed 201904-26]. Available from: https://actamont.tuke.sk/pdf/2010/s1/11rosova.pdf

[7] STRAKA, M. Alfa, a.s. distribution logistics system, Acta Montanistica Slovaca [online]. 2010, vol. 15, no. 1, pp. 34-43 [viewed 2019-04-26]. Available from: https://actamont.tuke.sk/pdf/2010/s1/7straka.pdf 
[8] CHROMJAKOVÁ, F., BOBÁK, R., HRUŠECKÁ, D. Production process stability - core assumption of INDUSTRY 4.0 concept. In The 5 th International Conference on Manufacturing, Optimization, Industrial and Material Engineering 2017. Milwaukee: Curran Associates, Inc., 2017, pp. 143-154.

[9] VILAMOVÁ, Š., BESTA, P., KOZEL, R., PIECHA, M., VANĚK, M., SAMOLEJOVÁ, A., JANOVSKÁ, K., ČECH, M.: Increasing the efficiency of production of iron by means of reduction of harmful elements, Metalurgija, 2015, vol. 54 , no. 4 .

[10] SANIUK, S., SAMOLEJOVA, A., SANIUK, A., LENORT, R. Benefits and barriers of participation in production networks in a metallurgical cluster - research results, Metalurgija, 2015, vol. 54, no. 3, pp. 567-570.

[11] DULINA, L., EDL, M., FUSKO, M., RAKYTA, M., SULIROVA, I. Digitization in the Technical Service Management System. MM Science Journal. No. 1, 2018, pp. 2260 - 2266.

[12] STRAKA, M., LENORT, R., KHOURI, S., FELIKS, J. Design of Large-Scale Logistics Systems Using Computer simulation hierarchic structure, International Journal of Simulation Modelling [online]. 2018. vol. 17, no. 1, pp. 105-118 [viewed 2018-09-27]. Available from: DOI: 10.2507/IJSIMM17(1)422

[13] TREBUNA, P., PEKARCíKOVA, M., EDL, M. Digital value stream mapping using the Tecnomatix Plant Simulation software. International Journal of Simulation Modelling - Wolkersdorf im Weinvierte, DAAAM International Vienna vol. 18, no. 1 (2019), s. 19-32 [print].

[14] KUPEROVÁ, M., ZATROCHOVÁ, M. Logistics conceptions in the production management in small-and mediumsized industrial companies in the Slovak republik. In Toyotarity. Change management. $1^{\text {st }}$ ed. Alba lulia, Romania: Aeternitas Publishing House, 2014, s.135-146.

[15] BÁRDY, M., KUDRNA, J., ŠRÁMKOVÁ, B.B., EDL, M. Interactive game supporting SMED method, Applied Mechanics and Materials. 2014. vol. 474, pp. 141-146 